\title{
PERANCANGAN KONVERTER ARUS SEARAH TIPE PENURUN TEGANGAN DENGAN MOSFET SINKRON DAN TANPA MOSFET SINKRON
}

\author{
Muhammad Irfan Dzakwan*), Iwan Setiawan, Agung Warsito, dan Trias Andromeda \\ Departemen Teknik Elektro Universitas Diponegoro, \\ Jln. Prof. Sudharto, SH Kampus UNDIP Tembalang, Semarang 50275, Indonesia \\ ${ }^{*}$ E-mail: muhamadirfandzakwan@gmail.com
}

\begin{abstract}
Abstrak
Sistem elektronika saat ini membutuhkan sumber daya yang memiliki efisiensi tinggi. Konverter arus searah berfungsi untuk mengkonversi tegangan masukan arus searah menjadi tegangan keluaran arus searah dengan nilai yang berbeda, selain itu dapat juga digunakan untuk mengatur tegangan keluaran terhadap variasi beban. Peningkatan efisiensi pada konverter arus searah dapat dilakukan dengan mengganti saklar pasif yang berupa dioda dengan saklar aktif yang berupa MOSFET. Konverter arus searah yang telah menggunakan MOSFET sebagai pengganti dari dioda bisa disebut sebagai konverter arus searah sinkron. Pada penelitian ini merancang sebuah konverter arus searah tipe penurun tegangan. Perancagan alat pada penelitian ini akan mengaplikasikan metode sinkronisasi MOSFET dengan cara mengaktifkan kedua MOSFET secara bergantian dan bekerja pada besaran frekuensi yang sama. Pada penelitian ini akan dilakukan perbandingan efisiensi antara konverter arus searah dengan MOSFET sinkron dan tanpa MOSFET sinkron. Pada konverter arus searah tipe penurun tegangan tanpa MOSFET sinkron semakin tinggi duty cycle maka akan semakin tinggi nilai efisisiensinya. Pada konverter arus searah dengan MOSFET sinkron nilai efisiensi cenderung stabil pada duty cycle berapapun. Pada penelitian ini didapatkan hasil bahwa konverter arus searah tipe penurun tegangan dengan MOSEFT sinkron lebih efisien daripada konverter arus searah tipe penurun tegangan tanpa MOSFET sinkron.
\end{abstract}

Kata kunci : Konverter arus searah, sinkronisasi MOSFET, efisiensi.

\begin{abstract}
In this modern electronics systems require power sources that have high efficiency.. Direct current converter serves to convert the direct current input voltage into direct current output voltage with different values, but it can also be used to adjust the output voltage to the load variation. Increasing efficiency in direct current converter can be done by replacing passive switch in the form of diode with active switch in the form of MOSFET. Direct current converters that have used MOSFETs instead of diodes may be referred to as synchronous rectification. In this research, designing a synchronous buck converter.The synchronous direct current converter operates by switching the two MOSFETs in turn and working on the same frequency. In this research will be an efficiency comparison between direct current converter with synchronous MOSFET and without sync MOSFET. In a buck converter the higher the duty cycle that the greater the efficiency. In a with synchronous buck the efficiency values tend to be stable at any duty cycle. In this research, it was found that the direct current converter of the voltage-lowering type with synchronous MOSEFT is more efficient than the direct current converter of the voltage-lowering type without the synchronous MOSFET.
\end{abstract}

Keyword : direct current converter, synchronous MOSFET, efficiency

\section{Pendahuluan}

Sistem elektronika saat ini membutuhkan sumber daya yang memiliki efisiensi tinggi. Penggunaan regulator linier dengan berdasarkan prinsip pembagi tegangan atau pembagi arus pada sumber daya dinilai sudah tidak efisien lagi karena hanya bertujuan untuk mendapatkan nilai ouput yang lebih kecil dari nilai input. Untuk kebutuhan daya yang lebih tinggi digunakan switching regulator.
Switching regulator menggunakan semikonduktor sebagai saklar, saklar tersebut beralih dari off ke on secara cepat atau bekerja pada frekuensi tinggi. Konverter arus searah berfungsi untuk mengkonversi tegangan masukan arus searah menjadi tegangan keluaran arus searah dengan nilai yang berbeda, selain itu dapat juga digunakan untuk mengatur tegangan keluaran terhadap variasi beban.[1] Peningkatan efisiensi pada konverter arus searah dapat dilakukan dengan mengganti saklar pasif yang berupa dioda dengan saklar aktif yang berupa MOSFET [2]. 
Konverter arus searah yang telah menggunakan MOSFET sebagai pengganti dari dioda bisa disebut sebagai konverter arus searah sinkron. Konverter arus searah sinkron beroperasi dengan cara mengaktifkan kedua MOSFET secara bergantian dan bekerja pada besaran frekuensi yang sama. MOSFET dapat mengurangi rugi konduksi pada diode karena rugi konduksi pada MOSFET yang lebih rendah dari rugi konduksi terkait dengan dioda[3]. Pada penelitian ini akan dilakukan perbandingan efisiensi antara konverter arus searah dengan MOSFET sinkronisasi dan tanpa MOSFET sinkronisasi

\section{Metode}

Perancangan penelitian ini terdiri dari rangkaian konverter arus searah dengan MOSFET sinkronisasi dan tanpa MOSFET sinkronisasi, rangkaian penyearah, dan rangkaian kontrol pembangkit sinyal PWM.

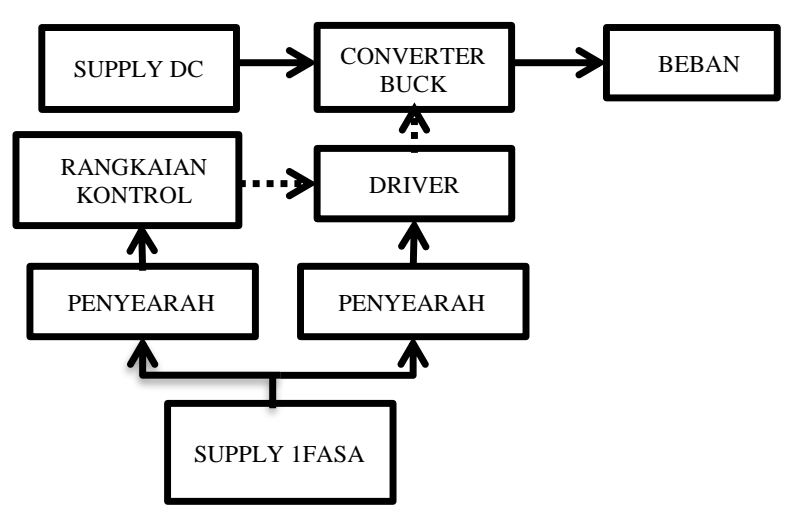

Gambar 1. Blok diagram konverter arus searah tanpa MOSFET sinkronisasi

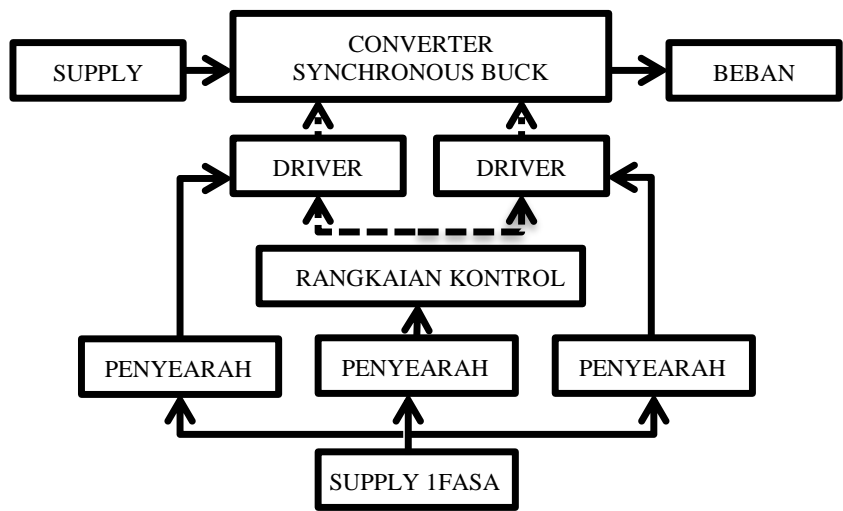

Gambar 2. Blok diagram konverter arus searah dengan MOSFET sinkronisasi
2.1. Perancangan Rangkaian Konverter Arus Searah Dengan MOSFET Sinkronisasi dan Tanpa MOSFET Sinkronisasi

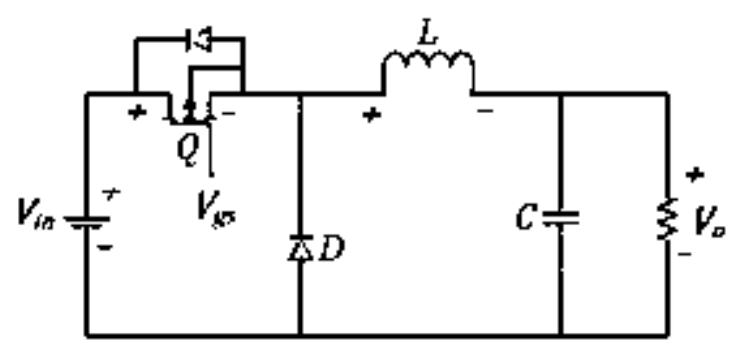

Gambar 3. Rangkaian konverter arus searah tipe penurun tegangan tanpa MOSFET sinkronisasi

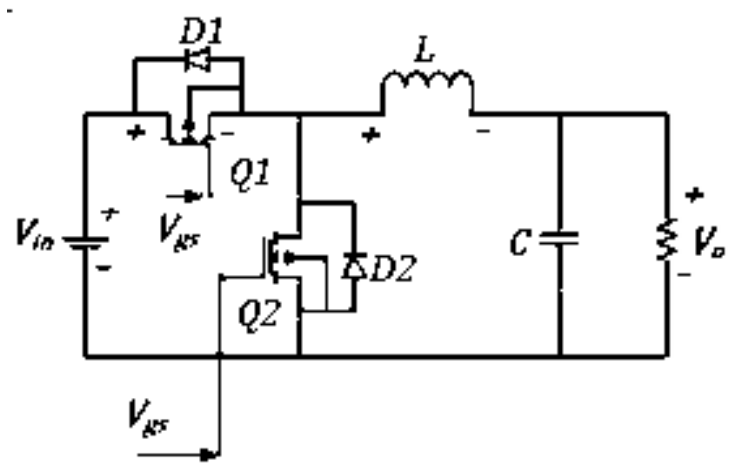

Gambar 4. Rangkaian konverter arus searah tipe penurun tegangan dengan MOSFET sinkronisasi

Komponen - komponen penyusun yang digunakan pada konverter arus searah dengan MOSFET sinkronisasi dan tanpa MOSFET sinkronisasi antara lain:

1. Sumber Tegangan Arus Searah

Sumber yang dipakai rangkaian konverter arus searah untuk menyuplai rangkaian arus searah didapat dari power supply. Sumber tegangan arus searah ini memeberikan tegangan sebesar $13,5 \mathrm{~V}$ untuk mensuplai

2. Saklar

Komponen pensaklaran yang digunakan pada konverter arus searah pada penelitian ini adalah MOSFET. Pemilihan MOSFET harus mempertimbangkan nilai tegangan dan arus operasi selain itu untuk pemilihan MOSFET sinkronisasi perlu diperhatikan juga tahanan dalamnya $R_{d s(o n) \text {. Tujuan }}$ pemilihan MOSFET dengan $\mathrm{R}_{\mathrm{ds}(\mathrm{on})}$ yang rendah agar terlihat perbedaan rugi daya yang terjadi. Tegangan masukan konverter arus searah adalah $13,5 \mathrm{~V}$.

MOSFET yang dipakai adalah MOSFET IRFP460 yang mempunyai tegangan breakdown Drain-Source $\mathrm{V}_{\text {(BR)DS }}$ adalah $500 \mathrm{~V}$ dan kemampuan arus drain maksimal 20 A, sehingga pemakaian MOSFET tipe IRFP460 ini aman untuk dipakai karena arus rata-rata yang dialirkan rangkaian daya yaitu 
dibawah 5 A [13]. Sedangkan pada MOSFET sinkronisasi digunakan MOSFET IRFZ44N yang mempunyai $\mathrm{R}_{\mathrm{ds}(\mathrm{on})}$ rendah yaitu $17,5 \mathrm{~m} \Omega$ dengan tegangan breakdown drain-source sebesar $55 \mathrm{~V}$ dan kemampuan arus drain maksimal 49 A [14].

3. Dioda yang digunakan adalah MUR460. Dioda ini dipilih karena mempunyai sifat ultrafast recovery dengan waktu pemulihan 75ns [12].

4. Induktor

Induktor yang digunakan pada konverter arus searah ini diperhitungkan nilainya untuk disesuaikan dengan parameter lain yang berhubungan. Induktor yang digunakan merupakan induktor jenis toroid yang dibuat dari kawat tembaga yang dililitkan pada inti ferit toroid.

$L_{\text {min }}=\frac{\left(V_{\text {in }}-V_{\text {out }}\right) \times D}{I_{L R} \times I_{\text {out }} \times f_{\text {sw }}}=\frac{(12-5) \times 0,416}{0.3 \times 5 \times 15000}=129.6 \mu \mathrm{H}$

Pemilihan nilai induktor lebih besar dari nilai induktor minimal $\left(\mathrm{L}>\mathrm{L}_{\min }\right)$ agar konverter arus searah bekerja pada Continuous Conduction Mode) (CCM). Pada penelitian ini digunakan induktor dengan nilai sebesar $5 \mathrm{mH}$.

5. Kapasitor

Kapasitor berfungsi sebagai filter tegangan untuk membatasi ripple tegangan yang disebabkan kenaikan nilai beban. Kapasitor yang digunakan untuk perancangan konverter arus searah ini bernilai $470 \mu \mathrm{F}$. Hal ini dilakukan untuk mendapatkan tegangan ripple puncak ke puncak kapasitor $\left(\Delta V_{0}\right)$ yang kecil.

$$
\begin{aligned}
C_{\text {min }} & =\frac{I_{L R} \times I_{\text {out } \text { max }}}{8 \times f_{\text {sw }} \times C_{V R} \times V_{\text {out }}} \\
& =\frac{0.3 \times 5}{8 \times 15000 \times 0.04 \times 5}=62.5 \mu \mathrm{F}
\end{aligned}
$$

Pada perhitungan kapasitor didapat nilai kapasitansi kapasitor sebesar $62,5 \mu \mathrm{F}$. Pada realisasinya kapasitor yang dipasang adalah $470 \mu \mathrm{F}$. Nilai kapasitansi sebesar $62,5 \mu \mathrm{F}$ tidak dapat ditemukan dipasaran, sehingga dipilih nilai kapasitansi kapasitor diatas nilai perhitungan. Pemilihan nilai kapasitansi kapasitor diatas nilai perhitungan bertujuan untuk mengurangi ripple tegangan keluaran.

\subsection{Rangkaian Penyearah}

Penyearah berfungsi sebagai pengubah tegangan arus bolak-balik (Alternating Current) menjadi tegangan arus searah (Direct Current). Rangkaian penyearah ini digunakan sebagai suplai rangkaian kontrol pembangkit sinyal PWM microcontroller dan rangkaian driver MOSFET. Gambar 4. adalah rangkaian penyearah yang digunakan pada penelitian ini.

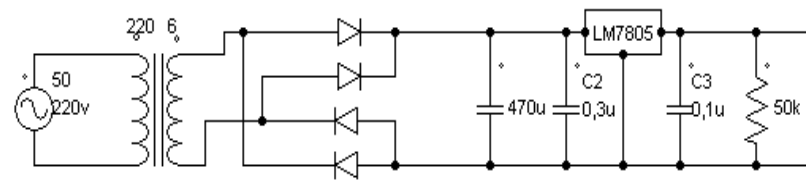

Gambar 5. Rangkaian Penyearah

Penyearah pada penelitian ini dilengkapi dengan kapasitor sebagai filter tegangan keluaran.

\subsection{Perancangan Rangkaian Kontrol}

Rangkaian kontrol terdiri dari rangkaian sistem minimum mikrokontroler ATTiny85 dan rangkaian driver MOSFET. Rangkaian kontrol menggunakan suplai dari 3 buah rangkaian penyearah dengan tegangan keluaran $5 \mathrm{~V}_{\mathrm{DC}}$ untuk menyuplai mikrokontroler dan tegangan $15 \mathrm{~V}_{\mathrm{DC}}$ untuk menyuplai rangkaian driver MOSFET.

\subsubsection{Sistem Minimum Kontroler}

Sistem minimum mikrokontroler adalah sebuah rangkaian elektronika sederhana yang terdiri dari komponen komponen dasar yang dibutuhkan oleh mikrokontroller agar dapat berfungsi dengan baik. Mikrokontroller digunakan sebagai pembgangkit sinyal PWM yang digunakan untuk pensaklaran rangkaian daya.

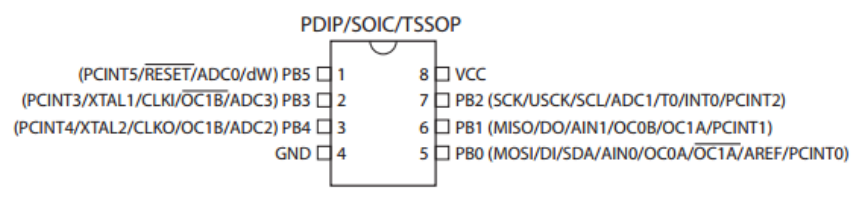

Gambar 6. Mikrokontroler ATTimy85 [7]

\subsubsection{Rangkaian Driver MOSFET}

Rangkaian TLP250 digunakan untuk mengisolasi dan menguatkan sinyal PWM tegangan 5 volt yang dibangkitkan mikrokontroller menjadi level tegangan yang lebih tinggi dengan sistem ground terpisah dan cukup untuk memicu MOSFET yang membutuhkan tegangan VGS $\pm 20 \mathrm{~V}$.

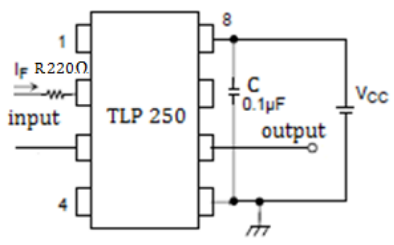

Gambar 7. Rangkaian TLP250 [15] 


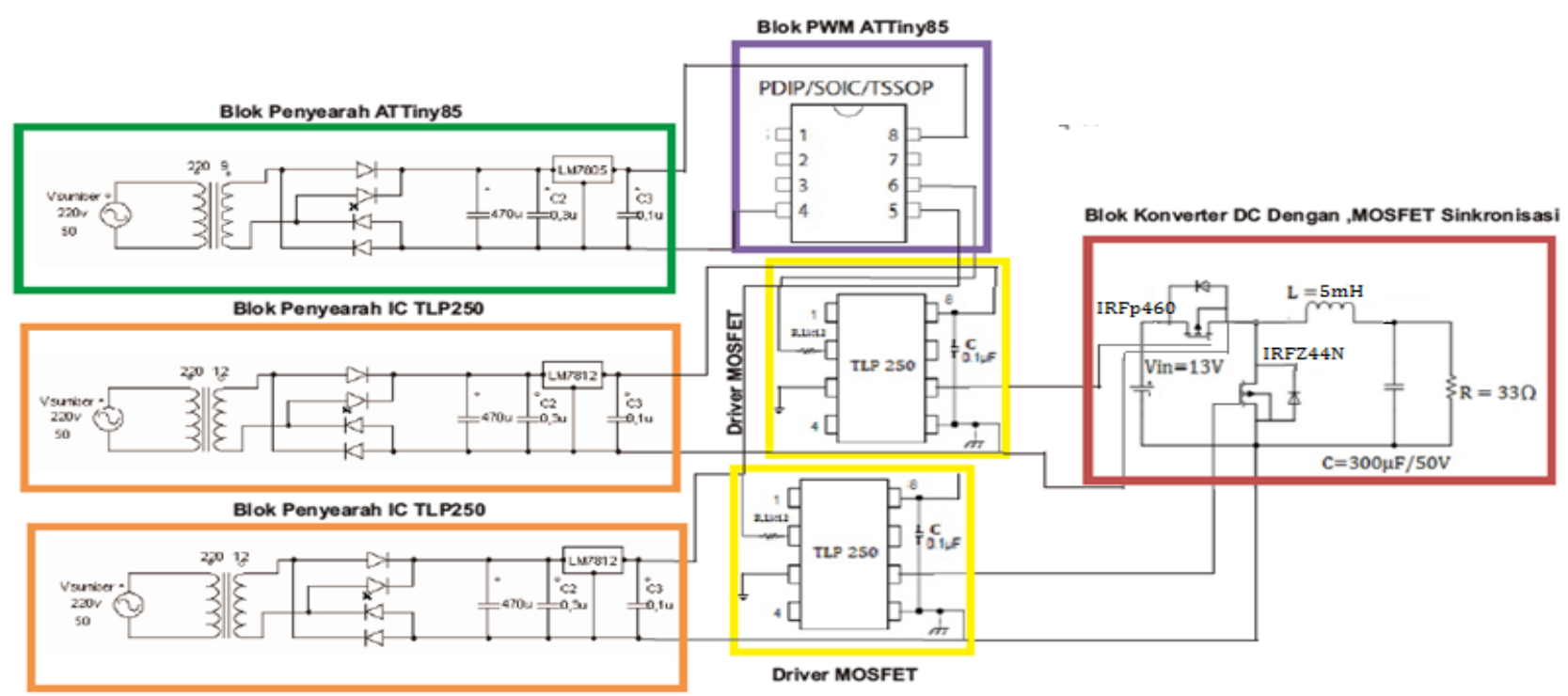

Gambar 8. Skema rangkaian keseluruhan

\section{Hasil dan Analisa}

\subsection{Pengujian Rankaian Kontrol}

Pengujian subbab ini akan membahas mengenai hasil pengujian nilai keluaran pada blok rangkaian control yang terdiri dari rangkaian PWM mikrokontroller, MOSFET Driver TLP250.

\subsubsection{Pengujian PWM Mikrokontroler}

Gambar 9 menunjukan output pin PWM dimana pengamatan dilakukan pada V/div500mV dan T/div $20 \mu \mathrm{s}$ dengan probe dikali 10 .

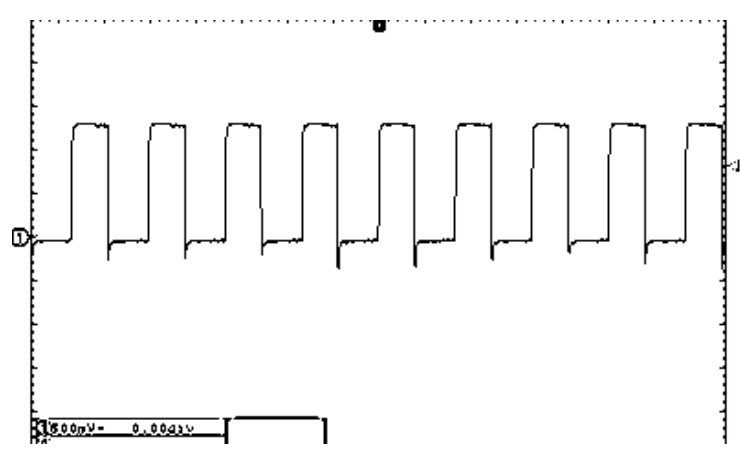

Gambar 9. Gelombang keluaran PWM D=45\%

\subsubsection{Pengujian Rangkaian MOSFET Driver TLP250}

Gambar 10 menunjukan output pin 6 dengan ground TLP250 dimana pengamatan dilakukan pada V/div 500mV dan T/div $10 \mu$ dengan probe dikali 10 .

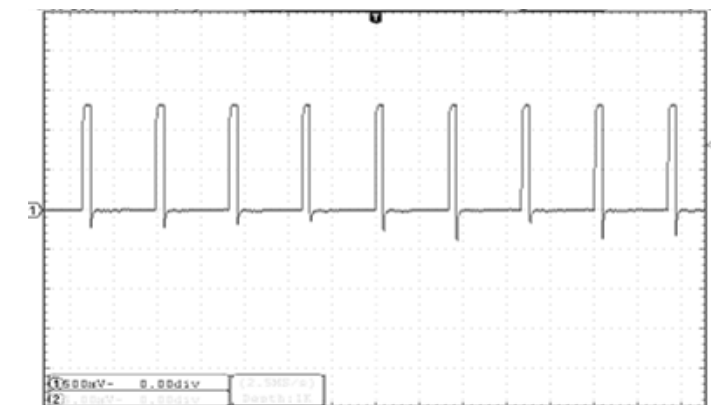

Gambar 10. Gelombang keluaran TLP250 D=10\%

\subsection{Pengujian Rangkaian Daya}

Pengujian rangkaian daya dilakukan dengan mengukur tegangan masukan, arus masukan, tegangan keluaran, arus keluaran, dan perhitungan efisiensi rangkaian konverter. Pengujian untuk dapat mengetahui efisiensi dari rangkaian konverter arus searah dengan MOSFET sinkron dan tanpa MOSFET sinkron.

\subsubsection{Pengujian Konverter Arus Searah Tipe Penurun Tegangan}

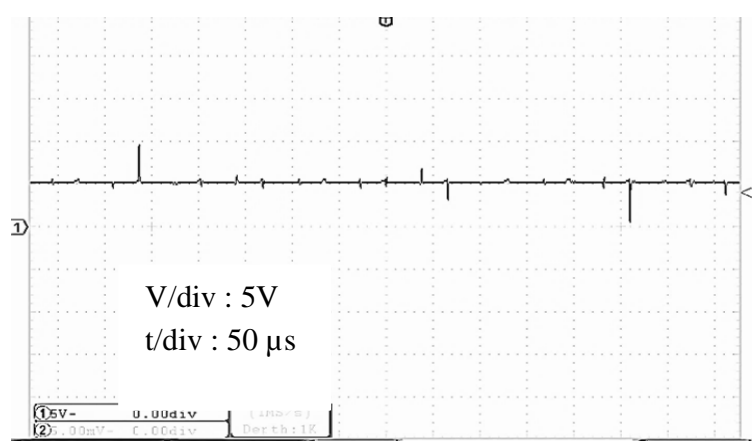

Gambar 11. Gelombang tegangan keluaran konverter 
Berdasarkan gambar 11 gelombang tegangan keluaran konverter berbentuk garis lurus yang merupakan bentuk dari gelombang tegangan arus searah.

Tabel 1. Hasil pengujian konverter arus searah tipe penurun tegangan

\begin{tabular}{ccccc}
\hline Duty Cycle $(\%)$ & $\boldsymbol{V}_{\text {in }}(\mathbf{V})$ & $\boldsymbol{I}_{\text {in }}(\boldsymbol{A})$ & $\boldsymbol{V}_{\boldsymbol{o}}(\boldsymbol{V})$ & $\boldsymbol{I}_{\mathbf{o}}(\boldsymbol{A})$ \\
\hline 10 & 13,58 & 0,0053 & 0,928 & 0,038 \\
20 & 13,58 & 0,022 & 2,12 & 0,096 \\
30 & 13,56 & 0,061 & 3,39 & 0,152 \\
40 & 13,56 & 0,123 & 4,59 & 0,21 \\
50 & 13,56 & 0,182 & 5,76 & 0,262 \\
60 & 13,56 & 0,246 & 7,00 & 0,318 \\
70 & 13,55 & 0,31 & 8,20 & 0,373 \\
80 & 13,55 & 0,388 & 9,40 & 0,427 \\
90 & 13,54 & 0,464 & 10,80 & 0,489 \\
96,8 & 13,54 & 0,497 & 11,3 & 0,513 \\
\hline
\end{tabular}

Tabel 1 adalah tabel pengujian saat konverter arus searah tipe penurun tegangan tanpa MOSFET sinkronisasi dibebani dengan tahanan $20 \Omega$.

\subsubsection{Pengujian Konverter Arus Searah Tipe Penurun Tegangan Dengan MOSFET Sinkron}

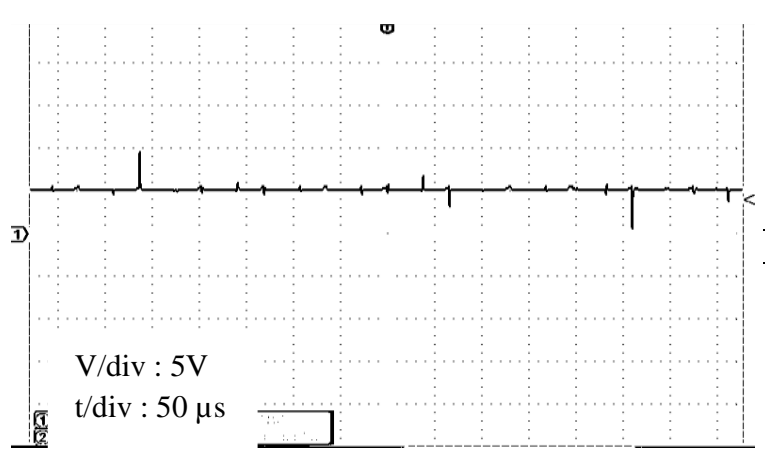

Gambar 12. Gelombang tegangan keluaran konverter arus searah tipe penurun tegangan dengan MOSFET sinkron

Berdasarkan gambar 11 gelombang tegangan keluaran konverter berbentuk garis lurus yang merupakan bentuk dari gelombang tegangan arus searah.

Tabel 2. Hasil pengujian konverter arus searah tipe penurun tegangan dengan MOSFET sinkronisasi

\begin{tabular}{ccccc}
\hline Duty Cycle $(\%)$ & $\boldsymbol{V}_{\text {in }}(\boldsymbol{V})$ & $\boldsymbol{l}_{\text {in }}(\boldsymbol{A})$ & $\boldsymbol{V}_{\mathbf{o}}(\boldsymbol{V})$ & $\boldsymbol{I}_{\mathbf{o}}(\boldsymbol{A})$ \\
\hline 10 & 13,45 & 0,008 & 1,43 & 0,064 \\
20 & 13,45 & 0,028 & 2,64 & 0,118 \\
30 & 13,45 & 0,07 & 3,82 & 0,172 \\
40 & 13,44 & 0,12 & 5,18 & 0,225 \\
50 & 13,44 & 0,18 & 6 & 0,271 \\
60 & 13,42 & 0,251 & 7,23 & 0,33 \\
70 & 13,42 & 0,314 & 8,47 & 0,381 \\
80 & 13,42 & 0,383 & 9,49 & 0,426 \\
90 & 13,41 & 0,465 & 10,82 & 0,487 \\
96,8 & 13,41 & 0,512 & 11,6 & 0,525 \\
\hline
\end{tabular}

\subsection{Perbandingan Efisisensi}

Berdasarkan Tabel 1, dapat dihitung rugi-rugi yang terjadi saat proses pensaklaran pada konverter arus searah tipe penurun tegangan tanpa MOSFET sinkronisasi $\left(P_{R e c D}\right)$.

Tabel 3. Rugi-rugi yang terjadi saat proses pensaklaran pada konverter arus searah tanpa MOSFET sinkronisasi.

\begin{tabular}{ccccc}
\hline $\begin{array}{c}\text { DUTY } \\
\text { CYCLE } \\
(\%)\end{array}$ & $\boldsymbol{P}_{\text {CONQ }}$ & $\boldsymbol{P}_{\text {SWQ }}$ & $\boldsymbol{P}_{\text {COND }}$ & $\boldsymbol{P}_{\text {RECD }}$ \\
\hline 10 & 0,00003898 & 0,0359 & 0,000483013 & 0,036432001 \\
20 & 0,00049766 & 0,0806 & 0,001220244 & 0,082357908 \\
30 & 0,00187142 & 0,1117 & 0,001929208 & 0,115520632 \\
40 & 0,0047628 & 0,1323 & 0,002665354 & 0,139728154 \\
50 & 0,0092669 & 0,1375 & 0,003325346 & 0,150142286 \\
60 & 0,01638208 & 0,1335 & 0,004036107 & 0,153978195 \\
70 & 0,02629538 & 0,1174 & 0,004730684 & 0,148521065 \\
80 & 0,03938306 & 0,0896 & 0,005415556 & 0,13446862 \\
90 & 0,05810640 & 0,0513 & 0,006197312 & 0,115648715 \\
96,8 & 0,06878185 & 0,01723 & 0,006501475 & 0,092520125 \\
\hline
\end{tabular}

Berdasarkan Tabel 2, dapat dihitung rugi-rugi yang terjadi saat proses pensaklaran pada konverter arus searah tipe penurun tegangan dengan MOSFET sinkronisasi $\left(P_{\text {RecSM }}\right)$.

Tabel 4. Rugi-rugi yang terjadi saat proses pensaklaran pada konverter arus searah dengan MOSFET sinkronisasi.

\begin{tabular}{|c|c|c|c|c|c|}
\hline Duty cycle (\%) & $P_{\text {conQ1 }}$ & $P_{\text {SWQ1 }}$ & $P_{\text {conQ2 }}$ & $P_{\text {conD2 }}$ & $P_{\text {RecSM }}$ \\
\hline 10 & 0,00011059 & 0,001081 & 0,00098095 & $5,99 \mathrm{E}-06$ & 0,00217 \\
\hline 20 & 0,00075189 & 0,001994 & 0,00295871 & 2,21E-05 & 0,00572 \\
\hline 30 & 0,00239630 & 0,002906 & 0,00548753 & $4,83 \mathrm{E}-05$ & 0,01083 \\
\hline 40 & 0,0054675 & 0,003802 & 0,00802355 & $8,42 E-05$ & 0,01737 \\
\hline 50 & 0,00991453 & 0,004579 & 0,00965675 & 0,00012 & 0,02427 \\
\hline 60 & 0,0176418 & 0,005577 & 0,01137896 & 0,00018 & 0,03478 \\
\hline 70 & 0,02743542 & 0,006438 & 0,01124852 & 0,00025 & 0,04537 \\
\hline 80 & 0,03919881 & 0,007199 & 0,00916272 & 0,00031 & 0,05588 \\
\hline 90 & 0,05763206 & 0,008230 & 0,0055711 & 0,00041 & 0,07184 \\
\hline 96,8 & 0,07203735 & 0,0088725 & 0,001413956 & 0,000476 & 0,082799 \\
\hline
\end{tabular}

Berdasarkan Tabel 3 dan 4 dapat dilakukan perbandingan daya yang hilang akibat proses konduksi antara konverter arus searah tipe penurun tegangan dengan MOSFET sinkronisasi $\left(P_{\text {RecSM }}\right)$ dengan konverter arus searah tipe penurun tegangan tanpa MOSFET sinkronisasi $\left(P_{R e c D}\right)$

Tabel 5. Perbandingan rugi daya konduksi antara konverter arus searah dengan MOSFET sinkronisasi dan konverter arus searah tanpa MOSFET sinkronisasi.

\begin{tabular}{ccc}
\hline Duty cycle $(\%)$ & $P_{\text {RecSM }}(\mathrm{W})$ & $P_{\operatorname{Rec} D}(\mathrm{~W})$ \\
\hline 10 & 0,002179 & 0,036432001 \\
20 & 0,005727 & 0,082357908 \\
30 & 0,010839 & 0,115520632 \\
40 & 0,017378 & 0,139728154 \\
50 & 0,024278 & 0,150142286 \\
60 & 0,034783 & 0,153978195 \\
70 & 0,045372 & 0,148521065 \\
80 & 0,05588 & 0,13446862 \\
90 & 0,071844 & 0,115648715 \\
96,8 & 0,082799 & 0,092520125 \\
\hline
\end{tabular}


Berdasarkan data pada Tabel 4.6 dapat diperoleh efisiensi pada konverter arus searah tipe penurun tegangan dengan MOSFET sinkronisasi yang dihitung menggunakan persamaan:

$$
\eta_{S M}=\frac{P_{\text {out }}}{P_{\text {out }}+P_{\text {conQ1 }}+P_{\text {swQ1 }}+P_{\text {conQ2 }}+P_{\text {conD2 }}}
$$

dan konverter arus searah tipe penurun tegangan tanpa MOSFET sinkronisasi yang dihitung menggunakan persamaan:

$$
\eta_{D}=\frac{P_{\text {out }}}{P_{\text {out }}+P_{\text {conQ }}+P_{\text {swQ }}+P_{\text {conD }}}
$$

Maka didapat hasil sebagai berikut:

Tabel 6. Perbandingan efisiensi antara konverter arus searah dengan MOSFET sinkronisasi dan konverter arus searah tanpa MOSFET sinkronisasi.

\begin{tabular}{ccc}
\hline Duty cycle (\%) & $\eta_{D}$ & $\eta_{S M}$ \\
\hline 10 & 0,491854 & 0,976743 \\
20 & 0,711912 & 0,981948 \\
30 & 0,816867 & 0,983771 \\
40 & 0,873392 & 0,985309 \\
50 & 0,909513 & 0,985289 \\
60 & 0,935303 & 0,985631 \\
70 & 0,95369 & 0,986135 \\
80 & 0,967584 & 0,986366 \\
90 & 0,978571 & 0,986549 \\
96,8 & 0,98429 & 0,986586 \\
\hline
\end{tabular}

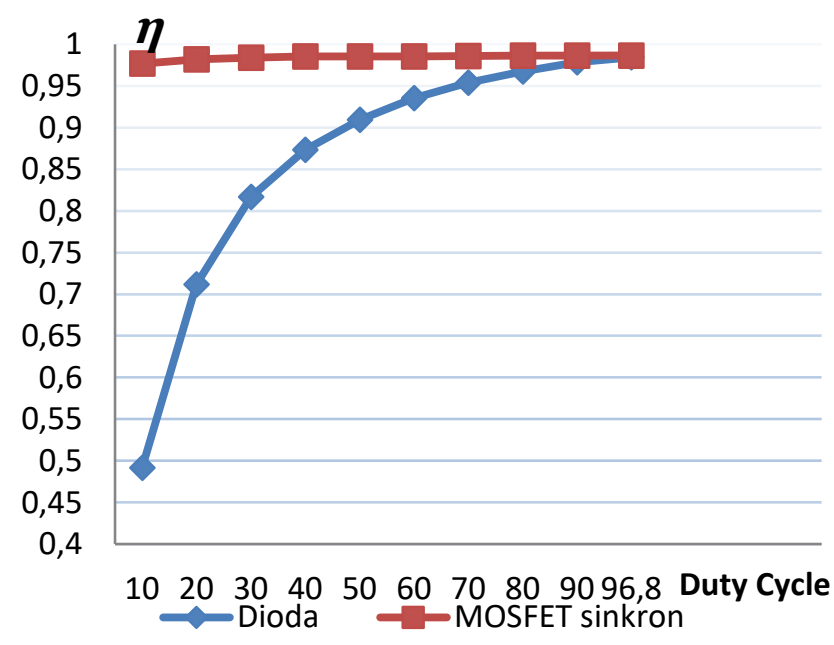

Gambar 13. Grafik Perbandingan Efisiensi konverter arus searah tipe penurun tegangan dengan MOSFET sinkronisasi $(\eta S M)$ dan konverter arus searah tipe penurun tegangan tanpa MOSFET $\operatorname{sinkronisasi}\left(\eta_{D}\right)$

Berdasarkan Gambar 13 dan Tabel 6 di atas terlihat bahwa nilai duty cycle berbanding lurus dengan efisisensi yang dihasilkan dari konverter, dan terlihat bahwa konverter arus searah yang menggunakan MOSFET sinkron memiliki efisiensi yang lebih tinggi dibandingkan dengan konverter arus searah tipe penurun tegangan tanpa MOSFET sinkron.

\section{Kesimpulan}

Rugi konduksi yang terjadi pada konverter arus searah penurun tegangan tanpa MOSFET sinkron menunjukan nilai $0,1501 \mathrm{~W}$ pada duty cycle $50 \%$, sedangkan pada konverter dengan MOSFET sinkron menunjukan 0,0242 $\mathrm{W}$, dari data tersebut menunjukan bahwa konverter arus searah tanpa MOSFET sinkron menghasilkan rugi daya konduksi yang lebih besar. Nilai rugi konduksi pada dioda akan semakin kecil ketika duty cycle diperbesar. Hal ini dikarenakan rugi konduksi dipengaruhi nilai duty cycle.Pada penelitian ini didapatkan hasil bahwa konverter arus searah tipe penurun tegangan dengan MOSFET sinkron lebih efisien daripada konverter arus searah tipe penurun tegangan tanpa MOSFET sinkron. Penelitian ini dapat dikembangkan lagi dengan mengaplikasikan metode ZVT (Zero Current Transition) synchronous buck converter untuk mengurangi rugi-rugi dan meningkatkan efisiensi.

\section{Referensi}

[1] Hart, Daniel W., "Power Electronics - DC-DC Converter", Valparaiso University, Valparaiso, Indiana, 2011.

[2] Jaunay, Serge and Brown, Jess, "DC to DC Design Guide", Vishay Siliconix, AN607, 71917.

[3] Rashid, Muhammad H., "Power Electronics Handbook", University of Florida, Florida, 2001.

[4] Mohan, Ned, "Power Electronic - A First Course", John Wiley \& Sons, Inc., University of Minnesota, Minneapolis, 2012.

[5] Cheng, Yuhua and Hu, Chenming, "\$2.1 MOSFET classification and operation", MOSFET modeling \& BSIM3 user's garuide, Springer. p. 13, ISBN 0-79238575-6(1999).

[6] Atmel Corporation "Atmel 8-bit AVR Microcontroller with $2 / 4 / 8 \mathrm{~K}$ Bytes In-System Programmable Flash", Revision: 2586Q-AVR-08, Agustus 2013

[7] Dittmer, Greg "Synchronous Boost Converter Provide High Voltage Without The Heat", Linear Technology Magazine, January 2008.

[8] "Capacitor Reports-Resistor Reports-Electronic Analysis-Dennis Zogbi-Paumanok Publications", Paumanokgroup.com, 2013-11-08, Retrieved 2014-0302.

[9] Vishay General Semiconductor, "1N4001 thru 1N4007", Document Number: 88503, Revision: 23-Feb-11.

[10] Fairchild Semiconductor, "LM78XX/LM78XXA 3Terminal 1A Positive Voltage Regulator", Fairchild Semiconductor Corporation, 2006.

[11] On Semiconductor, "MUR405, MUR410, MUR415, MUR420, MUR440, MUR460",

[12] Nell Semiconductor, "IRF460 Series",

[13] International Rectifier, IRFZ44N,

[14] TOSHIBA Photocoupler GaAlAs Ired \& Photo-IC, TLP250, 2004. 